\title{
TRAP1 is Involved in Cell Cycle Regulated by Retinoblastoma Susceptibility Gene (RB1) in Early Hypoxia and has Variable Expression Patterns in Human Tumors
}

\author{
Jiangting $\mathrm{Hu}^{1,{ }^{*}, \#}$, Ern $\mathrm{Yu} \operatorname{Tan}^{1, \dagger, \#}$, Leticia Campo ${ }^{1}$, Russell Leek ${ }^{1}$, Zainina Seman ${ }^{1, \ddagger}$, \\ Helen Turley ${ }^{1}$, Domenico Delia ${ }^{2}$, Alfredo Cesario ${ }^{3,4}$, Kevin Gatter ${ }^{1}$ and Francesco Pezzella ${ }^{1}$ \\ ${ }^{1}$ Nuffield Division of Clinical Laboratory Sciences, Radcliffe Department of Medicine, University of Oxford, \\ John Radcliffe Hospital, Oxford, OX3 9DU, UK; ${ }^{2}$ Department of Experimental Oncology, Fondazione IRCCS \\ Istituto Nazionale Tumori, Via G. Venezian 1, 20133 Milano, Italy; ${ }^{3}$ Division of General Thoracic Surgery, \\ Catholic University; ${ }^{4}$ Rehabilitative Pneumology, IRCCS, San Raffaele Pisana, Rome, Italy
}

\begin{abstract}
Tumor necrosis factor receptor associated protein 1(TRAP1) is a member of the Hsp90 family that acts as a molecular chaperon to the tumor suppressor retinoblastoma susceptibility gene (RB1). We have previously demonstrated that TRAP1-positive cells contain a high level of cell proliferating genes, whilst TRAP1-negative cells contain a high level of genes involved in cell cycles and metastases. In this study, we performed a functional analysis of TRAP1 which focused on its regulation within a cell cycle in relation to RB1. Following a heat shock, TRAP1 translocates to the nucleus and chaperons RB1. When TRAP1 is silenced by siRNA, or prevented from entering the nucleus in hypoxic cells, formation of RB1/E2F1 complexes is impaired and cell cycle activity is promoted by deregulating the G1/S transition. Inhibition of the nuclear translocation of TRAP1 with geldanamycin abrogates its ability to maintain RB1 in a form that associates with E2F1. Restoration of TRAP1 expression reverses these effects. We analysed TRAP1/RB1 expression on 630 tumors by immunohistochemical staining and found TRAP1 lost in some types of cancer, such as non-small cell lung cancer and breast cancer, and the positive correlation of TRAP1 expression in nuclear and cytoplasm with RB1 was observed. Clinico-pathological data showed that breast carcinoma patients lacking nuclear TRAP1 have a shorter disease free survival. Our data suggests that nuclear translocation of TRAP1 is crucial for its function as a chaperon. The loss of TRAP1 expression in certain types of cancer may provide the growth advantage due to the lost control at cell cycle check point.
\end{abstract}

Keywords: TRAP1, RB1, cell cycle, chaperon, hypoxia.

\section{INTRODUCTION}

Tumor necrosis factor receptor associated protein 1 (TRAP1) is a heat shock protein 75 (HSP75) highly homologous to HSP90 and chaperons RB1 [1, 2]. Its association with RB1 is evident either during the $M$ phase of the cell cycle or by re-locating into the nucleus following a heat shock, where it refolds denatured RB1 to its active conformation [1]. Mostly, TRAP1 is localised in mitochondria [3] acting as a substrate for the serine/threonine kinase PINK1 [4]. Other localizations include the TNF receptor on cell membranes [5], the cytosol and the endoplasmic reticulum [6]. It is therefore very likely that TRAP1 interacts with many other proteins and is involved in multiple pathways. Similar to HSP90, TRAP1 binds with ATP and is sensitive to Geldanamicyn, Radicicol and Shepherdin [3, 7].

\footnotetext{
*Address correspondence to this author at the Nuffield Division of Clinical Laboratory Science, Radcliffe Department of Medicine, University of Oxford, John Radcliffe Hospital, Oxford, OX3 9DU, UK; Tel: +44 (0)1865 220552; Fax:+44 (0)1865 228980; E-mail: jianting.hu@ndcls.ox.a.c.uk

"These authors share the equal contribution of this paper.

${ }^{\dagger}$ Current address: Department of General Surgery, Tan Tock Seng Hospital, Annex Block,11 Jalan Tan Tock Seng, Singapore 308433

${ }^{\ddagger}$ visiting fellow from Department of Pathology, Faculty of Medicine\& Science Health, UPM, 431001 Serdarg, Malaysia
}

Established TRAP1 functions also include binding to type 1 TNF receptor, interacting with the EXT1 and EXT2 proteins involved in hereditary multiple exostoses [8], and protecting cells from oxidative stress when phosphorylated $[4,9,10]$. A recent study revealed that TRAP1 is associated with the unfolded protein response (UPR) in oestrogen-receptor (ER) dysfunction indicating that mitochondria could be a potential regulator of the UPR in the ER through mitochondrial TRAP1 [11]. TRAP1 has also been reported to protect against apoptosis [12-14] and be involved in chemo-resistance by blocking drug-induced apoptosis [15]. Expression analysis with DNA microarrays has also revealed that TRAP1 mRNA transcription is regulated by C-MYC [16].

TRAP1 has been reported to be up regulated in some tumors $[7,15,17]$ and to be involved in oncogenesis by contributing to inhibition of apoptosis in cancer cells [7]. By data mining mRNA expression profiles of several types of tumor, we observed that TRAP1 expression was down-regulated in some types of lung, breast and pancreatic endocrine cancers compared to their corresponding normal tissues [1820]. 
It is well documented that the level of Heat shock proteins (HSPs) increases in tumors as a response to stress in order to restore the normal protein-folding environment. HSPs are essential in maintaining oncogenes in an active conformation. The dependence of cancer cells on normal cell functions, like the increase in levels of HSP, has recently been termed "non-oncogenic addiction" [21].

To understand the TRAP1 function in relation to its gene regulation, we have previously performed gene expression profiles on TRAP1 silence and reexpression tumor cell lines which found that TRAP1 regulates genes involved in cell cycle and metastases [2]. To further address the role of TRAP1 in the cell cycle regulation, in connection with RB1, we designed this study. As hypoxia is a shock situation occurring commonly in tumors [22], and hypo-phosphorylation of RB1 is an early event occurring within 6-12 hours of hypoxia [23], we raised the hypothesis that loss of TRAP1 might provide a growth advantage by impairing the re-activation of RB1 suppressor gene function when tumors cells are subject to such a shock. We investigated whether the expression of TRAP1 has any effect on the ability of RB1 to reduce cell proliferation during the first 16 hours of hypoxia. We also reviewed whether TRAP1 is involved in the cellular response to hypoxic shock, as well as heat shock, and whether its presence or absence affects any of the RB1 functions "in vitro" following the shocks.

\section{METHODS}

\section{Cell Culture}

Human Ductal breast carcinoma cell lines MCF7, T4TD and MDA231, human lung epithelial carcinoma cell line A549 and human colon adenocarcinoma cell line SW480, were cultured in 90\% Dulbecco's MEM + $10 \%$ FBS. Cells were split confluent cultures $1: 5$ every 4 days using tripsin/EDTA and incubated at $37^{\circ} \mathrm{C}$ with $5 \% \mathrm{CO}_{2}$ until further experiments were conducted.

\section{Study of Sub-Cellular Localization}

Wild type cells were grown as above and then cultured at normoxia for 48 hours. Cells were then incubated in hypoxia ( $0.1 \%$ oxygen) for $0,1,2,8,16$ and 24 hours. Harvested cells were then subjected to immunoblotting of whole cell lysate, nuclear/ cytoplasmic fractionation or stained for TRAP1 by immunoflurescence and examined by a confocal microscope. All experiments were repeated twice. The detailed protocols are in Supporting information S1.

\section{siRNA Transfection, Cell Culture and Flow Cytometry}

siRNA duplexes against the mRNA sequence targeting TRAP1 gene were designed and synthesised by Eurogentec (Eurogentec Inc, Belgium). Detailed sequences and procedure have been described previously [2]. Cells were then treated as wild type (WT), scramble (SCR) and RNA interference (RNAi). Cells were cultured at both normoxic for 48 hours and followed by hypoxic $\left(0.1 \%\right.$ of $\left.\mathrm{O}_{2}\right)$ incubation for 16 hours. Cells then were harvested for the following FACS assay. Cells were washed in PBS and fixed with ice-cold $70 \%(\mathrm{v} / \mathrm{v})$ ethanol for $1 \mathrm{~h}$ then spun down and resuspended in $1 \mathrm{ml}$ PBS containing propidium iodide $(5 \mu \mathrm{g} / \mathrm{ml})$ and RNase $A(2 \mathrm{mg} / \mathrm{ml})$. Stained cells were analysed by the Becton and Dickinson FACSCalibur flow cytometer using the CellQuest software. The data were expressed as a histogram with the DNA content $(\mathrm{FL} 2-\mathrm{H})$ along the $\mathrm{X}$-axis. The percentage of cells in $\mathrm{S}$ phase was obtained using the ModFit LT software from Verity House (Verity House Inc.USA). Three independent experiments were performed with A549 and two with SW480. The statistical analysis of the results is described in detail in the Supporting information S2.

\section{TRAP1 Expression Construct and Transfection}

The TRAP1 cDNA sequence BC023585 was identified from the PubMed database and obtained from GeneService (Cambridge, UK). The sequence was extracted and inserted into pcDNA4/HisMax, an expression vector (Invitrogen), and confirmed by sequencing (MWG sequencing service). MDA231 cells were transfected using the calcium phosphate coprecipitation method. Transfection mixtures were set up according to the manufacturer's instructions using $20 \mu \mathrm{g}$ of plasmid DNA (either TRAP1-pcDNA4 or empty vector pcDNA4). The media was replaced the next day and cells were cultured for $32 \mathrm{~h}$ in normoxia and then subjected to $16 \mathrm{~h}$ of hypoxia.

\section{TaqMan Real Time Quantitative PCR}

For each type of cancer we analysed 10 tumor samples and 10 corresponding normal tissue samples, as previously described [18]. All PCR primers and TaqMan probes were designed and purchased from $\mathrm{ABI}$ according to the company's assays-on-demand protocol. Their context sequence lists can be viewed in supporting information S3. Reactions were performed 
in triplicate and no false positive was detected in nontemplate control.

\section{Co-Immunoprecipitation \& Immunoblotting}

Cultured transfected or treated cells were lysed in buffer containing $50 \mathrm{mM}$ Tris- $\mathrm{HCl}(\mathrm{pH} 7.4), 120 \mathrm{mM}$ $\mathrm{NaCl}, 0.5 \%$ NP-40, $50 \mathrm{mM} \mathrm{NaF}, 5 \mathrm{mM}$ EDTA, $1 \mathrm{mM}$ DTT, $0.2 \mathrm{mM} \mathrm{Na}_{3} \mathrm{VO}_{4}$ and protease inhibitor cocktail (Roche). Samples were loaded onto either $7.5 \%$ or $10 \%$ SDS-PAGE gels for electrophoresis and immunoblotting. RB1 was immunoprecipitated from the extracts with immunostaining for TRAP1. Normal mouse IgG (Upstate, Billerica, MA, USA) was used as a negative non-specific lgG control.

\section{Immunostaining of Tissue Sections}

$4 \mu \mathrm{m}$ sections were cut from paraffin blocks and mounted on slides. The slides were first heated at $60^{\circ} \mathrm{C}$ for $12 \mathrm{~min}$ to melt the wax, dewaxed by immersing in citroclear twice (6min each time), and then rehydrated in graded ethanol solutions $(100 \%$ ethanol twice, then $50 \%$ ethanol once, $5 \mathrm{~min}$ each time). $0.3 \%$ hydrogen peroxide (VWR BDH, Leiscestershire, UK) was applied for $5 \mathrm{~min}$ at room temperature to quench any intrinsic tissue peroxidase activity that would falsely enhance the perioxidase reaction in the final step (secondary antibody used is conjugated with horse-radish peroxidase). Non-specific binding was blocked by incubating with $2.5 \%$ normal horse serum (Vector Laboratories, Burlingame, CA, USA). TRAP1 monoclonal antibody (Labvision, Fremont, CA, USA, 1:400 dilution) and RB1 monoclonal (Dako A/S, Gloustrup, Denmark, 1:50 dilution) were then applied. Substitution of the primary antibody with phosphatebuffered saline (PBS) served as a negative control. Slides were then washed in PBS twice before the secondary antibody was applied for $30 \mathrm{~min}$. In general, the Envision kit (Dako) was used.

\section{Patient Characteristics}

Tissue microarrayed $1 \mathrm{~mm}$ cores from 423 invasive breast carcinomas were collected from patients who underwent surgery at the John Radcliffe Hospital, Oxford, UK. Four separate cores were obtained from each tumor specimen; necrotic regions were avoided. This study has ethical committee approval (number C02.216). Cores that were incomplete or that did not include tumor epithelial cells were excluded. Only patients with operable breast carcinoma were included in this study. None had received any neoadjuvant therapy. Information of the patient characteristics including age, tumor size, grade, histology, nodal status, oestrogen-receptor (ER) status and human epidermal growth factor receptor-2 (HER2) status were collected from clinical and pathological records. The median age of the patients was 58 years (range 31 to 90 years). $76 \%$ of invasive tumors were classified as invasive ductal of no specific type, $7 \%$ as invasive lobular carcinoma, and $7 \%$ as other histological types (data was unavailable for the remaining 10\%). Median tumor grade, according to the Bloom and Richardson criteria, was 2 and the median tumor size was $21 \mathrm{~mm}$ (range 3 to $100 \mathrm{~mm}$ ). $41 \%$ of tumors were node positive and $66 \%$ were ER positive. Patients less than 50 years of age with node positive or ER negative tumors, or tumors more than $3 \mathrm{~cm}$ in size, were given adjuvant chemotherapy (cyclophosphamide, methotrexate and 5-fluorouracil (CMF). Patients with hormone responsive tumors, who were more than 50 years of age, were given endocrine therapy. Over a median follow-up period of 125 months (range 5.1 to 209.0 months), there were 172 relapses and 142 breast cancer-related deaths.

We stained a variety of normal and tumor tissue arrays produced within our laboratory. On each sample the percentage of cells showing cytoplasmic staining and nuclear staining was recorded. For positive cells, intensity of staining (again for nuclear end cytoplasmic) was recorded on a scale from 1 to 3 . For data analysis a case was considered as positive (for nuclear end/or cytoplasmic staining) where $10 \%$ or more cells demonstrated positive staining of an intensity of 2 or more. The detailed protocols and materials are in supporting information S4.

\section{Survival Analysis}

The relationship between TRAP1, RB1 and the various clinic-pathological parameters and hypoxic markers, was evaluated using either the chi square test or Fisher's exact test where appropriate. Kaplan-Meier survival curves were calculated using tumor recurrence (defined as the first re-appearance of tumor at any site following definitive treatment) as the endpoint. The difference between groups in the time interval to recurrence (disease-free survival) was calculated by means of a log rank test. All univariate and survival analyses were performed with GraphPadPrism version 4 (GraphPad software Inc., San Diego CA). The Cox proportional hazards regression model was used to identify independent prognostic factors for disease-free survival and was performed using the Stata package 
release 8.1 (Stata Corporation, 4905 Lakeway Drive, College Station, Texas 77845, USA). A 2-tailed P value was used in all analyses and a $P$ value of less than 0.05 was considered statistically significant.

\section{A}

\section{HYPOXIA}
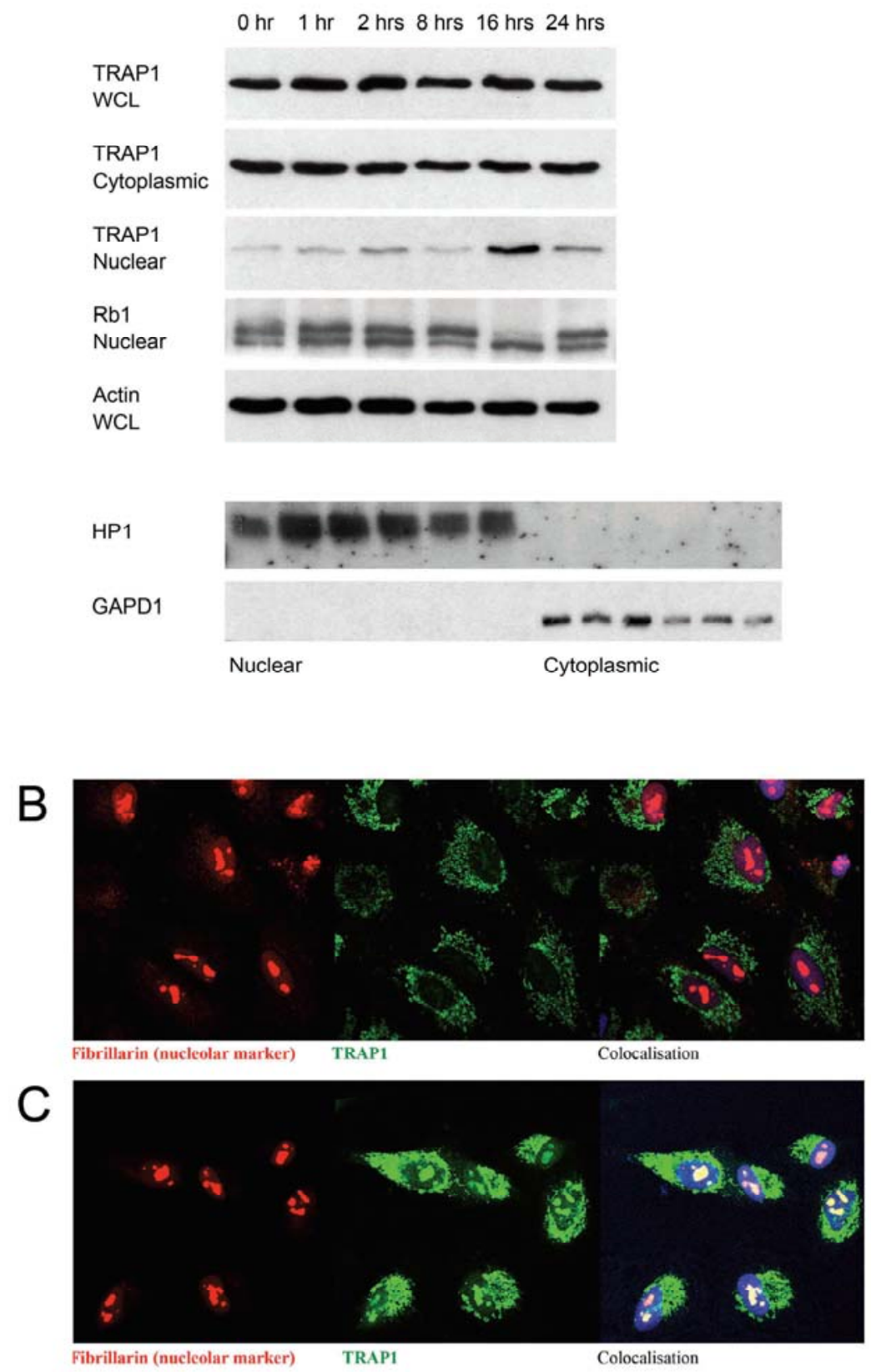

Figure 1: Effect of hypoxia on TRAP1 expression.

A. Hypoxia induced an increase in nuclear TRAP1 levels until 16h. No change in cytoplasmic or total cellular TRAP1 levels was observed. Whole cell lysates (WCL) and sub-cellular fractions were prepared from A549 lung carcinoma cells subjected to varying durations of hypoxia and resolved on 10\% SDS-PAGE electrophoresis and immunoblotted with anti-TRAP1 and antiRB1 antibodies. $\beta$-actin served a loading control for WCL. HP1a and GAPDH served as nuclear and cytoplasmic markers, respectively. A similar peak in nuclear TRAP1 levels was also observed in MCF7 and SW480 (shown in supplementary figure).

B. Immunofluorescent studies of A549 cells: nucleolar marker fibrillarin is in red/ TRAP1 staining (green) was predominantly in cytoplasm in normoxia. No increae by colocalisation between TRAP1 and Tom20 in normoxia.

C. After $16 \mathrm{hrs}$ of hypoxia, there is an increasing in nuclear TRAP1 levels in hypoxia by co-localisation between TRAP1 and Tom20 in hypoxia. 


\section{RESULTS}

\section{Hypoxia Affects TRAP1 Expression}

We exposed human lung adenocarcinoma A549 cells, human ductal breast carcinoma T47D, MCF 7 cells and human colon adenocarcinoma SW480 cells to various durations of hypoxia $(0.1 \%$ oxygen $)$ and performed nuclear/cytoplasmic fractionation followed by immunoblotting. In all of the cell lines, the levels of TRAP1 protein in the nuclear fraction were

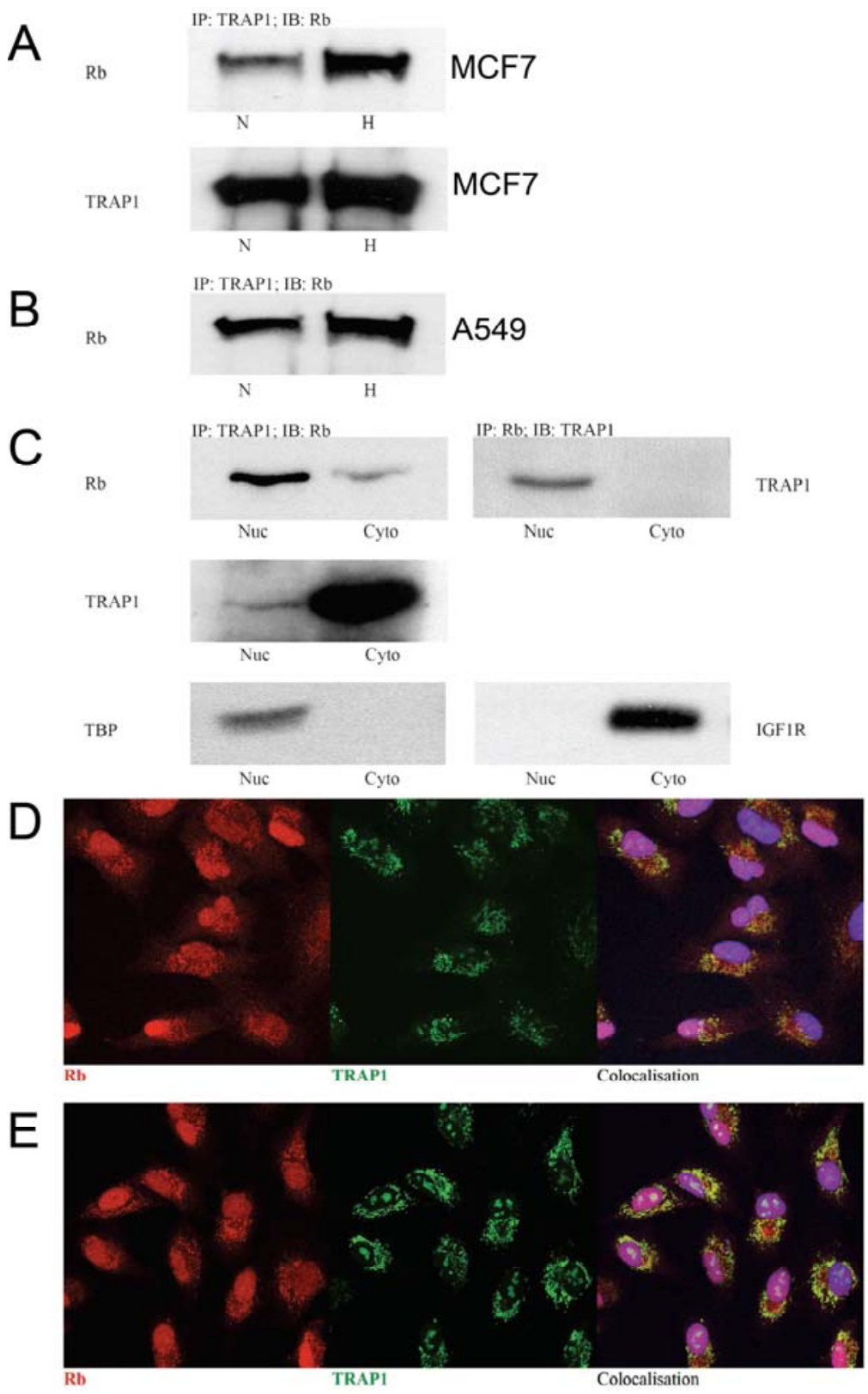

Figure 2: Interaction between TRAP1 and RB1.

A. An increase in TRAP1-RB1 co-immunocomplexes was observed in MCF7 cells subjected to hypoxia $(\mathrm{H})$, as compared to normoxic culture $(\mathrm{N})$. Lysates were immunoprecipitated with anti-TRAP1 antibody and immunoblotted with anti-RB1 antibiody. Immunoblotting of TRAP1 levels showed equivalent amounts of TRAP1 pulled down.

B. A similar increase in TRAP1-Rb co-immunocomplexes was observed in A549 cells in hypoxia.

C. Subcellular fractionation studies performed on MCF7 cells treated with 16h of hypoxia. TRAP1-RB1 co-immunocomplexes were observed predominantly in the nuclear fractions (Nuc) although much larger amounts of TRAP1 were present in the cytoplasm (Cyto). TBP and IGF1R were used as a nuclear and cytoplasmic marker respectively and demonstrated the quality of subcellular fractionation. Results here are representative of 2 similar experiments.

D. Immunofluorescent studies of A549 cells: In normoxia RB1 (red) is predominantly nuclear while TRAP1 (green) is cytoplasmic.

E. Following exposure to hypoxia co-localization between TRAP1 and RB1 is present in the nuclei of hypoxic cells. 
substantially increased after 16 hours of hypoxia but maintained a minimal in normoxia. Levels of TRAP1 in the whole cell lysate (WCL) and cytoplasmic fractions were not changed by hypoxia (Figure 1a). Immunofluorescence staining confirmed that TRAP1 nuclear translocation occurred in hypoxic cells when TRAP1 co-localizing inside the nucleolus was observed with fibrillarin (Figure 1b \& c).

\section{TRAP1-RB1 Interactions Occur Primarily in the Nucleus}

MCF7 cells were cultured in normoxia and then subjected to $16 \mathrm{~h}$ of hypoxia. Lysates were immunoprecipitated with anti-TRAP1 antibody, resolved on $10 \%$ SDS-PAGE electrophoresis and immunoblotted with anti-RB1 antibody. A direct physical association was observed between TRAP1 and RB1 in normoxia and a significant increase in TRAP1-RB1 co-immunocomplexes was observed following hypoxic treatment (Figure 2a). A similar increase in TRAP1 interactions with RB1 in hypoxia was also noted in A549 cells (Figure 2b). Subcellular fractionation was performed on MCF7 cells treated with $16 \mathrm{~h}$ of hypoxia and the interaction between TRAP1 and RB1 was evaluated in the nuclear and cytoplasmic fractions. Lysates were immunoprecipitated with antiTRAP1 antibody, resolved on 10\% SDS-PAGE electrophoresis and immunoblotted with anti-RB1

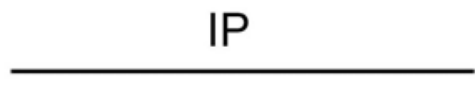

E2F1

IB $\mid \mathrm{Rb} 1$

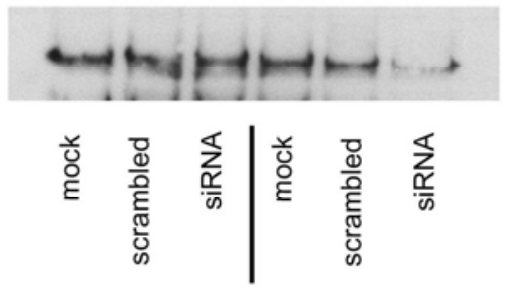

Normoxia Hypoxia

A

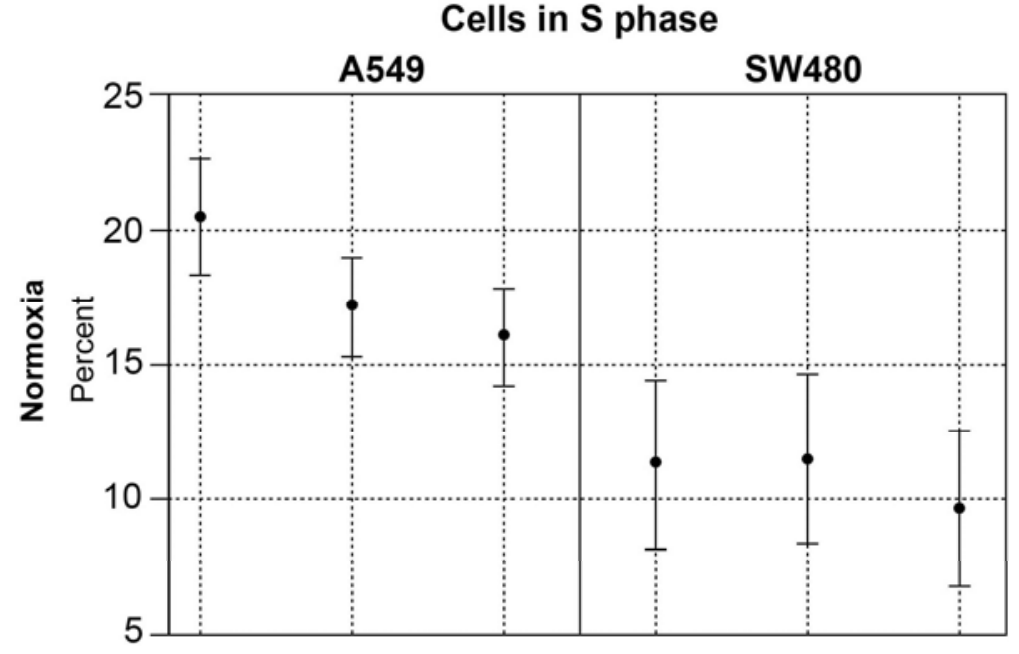

B

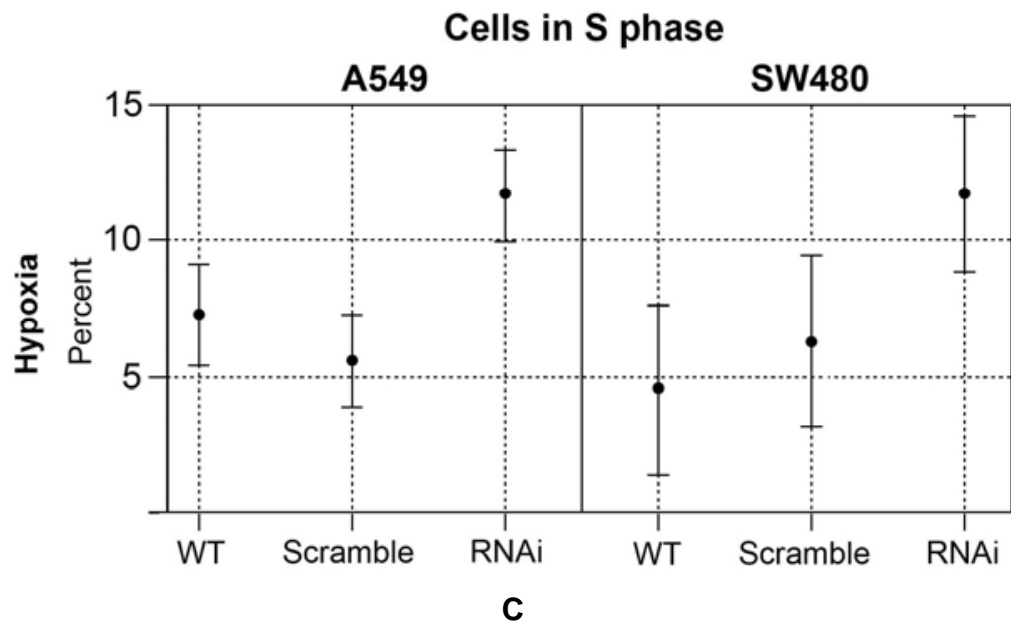

Figure 3: Effect of loss of TRAP1 on RB1/E2F1 interaction and cell cycle in A549 cells.

A. Reduced RB1-E2F1 co-immunocomplexes observed in hypoxia following TRAP1 knockdown in MCF7 cells. Lysates were immunoprecipitated with anti-E2F1 and immunoblotted with anti-RB1. Similar results were obtained using MCF7 cell line (see supporting information S5).

B, C. Flow cytometry analysis of A549 cells and SW480 transfected with siRNA against TRAP1 (Ri), scrambled control (SCR) or oligofectamine alone (Mock) and cultured in normoxia (B) or subjected to 16h of hypoxia (C). TRAP1 knockdown resulted in an increase in the $\mathrm{S}$ phase fraction in hypoxia. Blots here are representative of 3 similar experiments. Flow cytometry was done twice with A549 cells and once with SW480 cells. 
antibody. TRAP1-RB1 co-immunocomplexes were found predominantly within the nuclear lysates, although much greater amounts of TRAP1 were present within the cytoplasmic fractions (Figure 2c). Confocal microscopy on the A549 cell line confirms colocalization of TRAP1 and RB1 in the nuclei of hypoxic cells (Figure 2d \& 2e).

\section{Loss of TRAP1 Impairs RB1/E2F1 Interaction and Enhances Cell Cycle Activity}

The effect of TRAP1 loss on the interaction between $\mathrm{RB} 1$ and E2F1 was evaluated to demonstrate that TRAP1 is known to maintain RB1 in the hypophosphorylated form that binds E2F1. MCF7 cells were transfected with siRNA against TRAP1. Cells were cultured for $48 \mathrm{~h}$ in normoxia before either being subjected to $16 \mathrm{~h}$ of hypoxia or cultured for another $16 \mathrm{~h}$ in normoxia. The efficiency of siRNA knockdown was evaluated by TaqMan real time quantitative PCR, showing a loss of $90 \%$ of TRAP1 mRNA in treated cell lines compared to the wild type cells or those treated with a scrambled sequence. The levels of RB1 mRNA were not changed. TRAP1 proteins were almost completely absent in siRNA treated cells. RB1 protein was decreased in response to TRAP1 siRNA under normoxic and, more markedly, hypoxic conditions. The total E2F1 level was not affected (details in supporting information S5). Whole cell lysates were immunoprecipitated with anti-E2F1 antibody and immunoblotted with anti-RB1 antibody. TRAP1 knockdown resulted in a significant reduction of RB1/E2F1 co-immunocomplexes in hypoxia while the formation of RB1/E2F1 co-immunocomplexes was not affected by TRAP1 knockdown in normoxia. No change of RB1/E2F1 interaction was observed in mock and scrambled siRNA groups between normoxia and hypoxia (Figure 3a).

To investigate whether the diminished interaction between RB1 and E2F1 affected the cell cycle, we performed FACS analysis on A549 and SW480 cell lines treated as above. TRAP1 knockdown did not appear to have a significant effect on cell proliferation
A

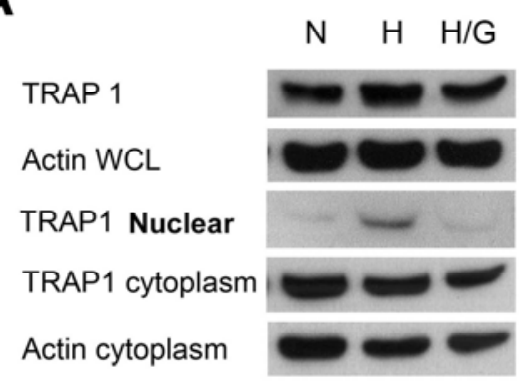

B

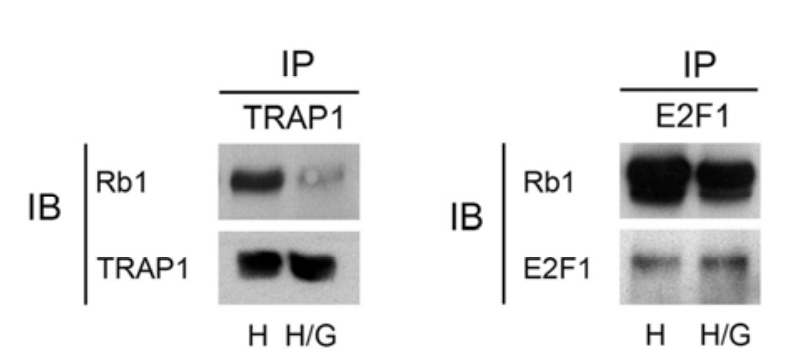

C

TRAP1 mRNA Expression

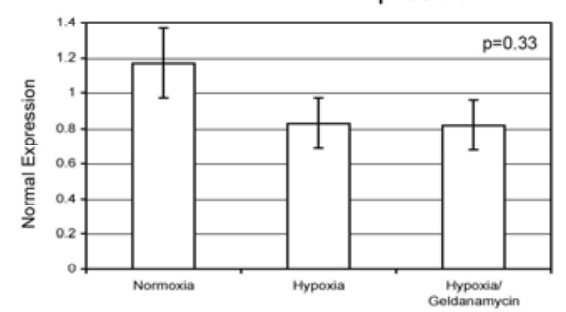

$\mathrm{Rb}$ mRNA Expression

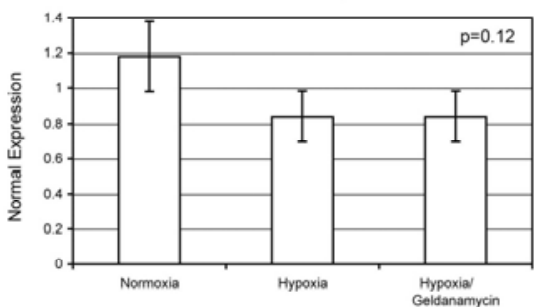

E2F1 mRNA Expression

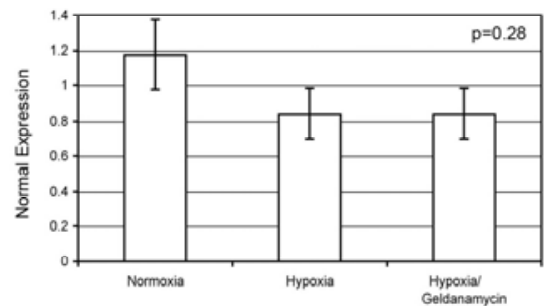

Figure 4: Geldanamycin inhibits TRAP1 activity by preventing TRAP1 nuclear translocation.

A. MCF7 cells were maintained in normoxia $(\mathrm{N})$, hypoxia for $16 \mathrm{hrs}(\mathrm{H})$ or hypoxia with $1 \mu \mathrm{M}$ Geldanamycin $(\mathrm{H} / \mathrm{G})$ and were immunoblotted as indicated. The total amount of TRAP1 in WCL is constant. TRAP1 translocates to the nucleus after hypoxia but the transfer is abolished by treatment with Geldanamycin. Actin served as a loading control. A further set of 3 experiments was performed on cell line A549 obtaining comparable results (data not shown).

B. MCF7 WCL cells subjected to $16 \mathrm{hrs}$ hypoxia $(\mathrm{H})$ or hypoxia plus $1 \mu \mathrm{M}$ Geldanamycin $(\mathrm{H} / \mathrm{G})$. Lysate are immunoprecipitate (IP) and immunoblotted (IB). After Geldanamycin treatment there is a reduction of TRAP1-RB1 and of RB1-E2F1 complexes. Treatment with Geldanamycin did not affect the total amount of TRAP1 and E2F1.

C. Treatment of MCF7 with $1 \mu \mathrm{M}$ Geldanamycin does not affect the levels of TRAP1, RB1 and E2F1 mRNA. RT-PCR: TRAP1, RB1 and E2F1 gene expression were normalised to 3 house-keeping genes ( $\beta$-actin, flotillin 2 and hypoxanthine). 
in normoxia $(P=0.55)$ (Figure $3 \mathbf{b})$. This was not unexpected since RB1-E2F1 co-immunocomplexes were not affected by TRAP1 knockdown. Consistent with the findings in Figure $\mathbf{3 a}$, reduced RB1 interaction with E2F1 in hypoxia, TRAP1 knockdown resulted in a statistically significant increase in the S-phase fraction in hypoxia $(P=0.01)$ (Figure $3 c$ ). These results suggested that TRAP1 was important in regulating G1/S transition when cells were exposed to hypoxia.

\section{Geldanamycin Inhibits TRAP1 Activity by Preventing TRAP1 Nuclear Translocation}

Because Geldanamycin inhibits both Hsp90 and TRAP1 [3], we explored whether its inhibitory effects on TRAP1 produced the same final effects on mRNA and protein depletion. MCF7 cell treatment with 1uM

A

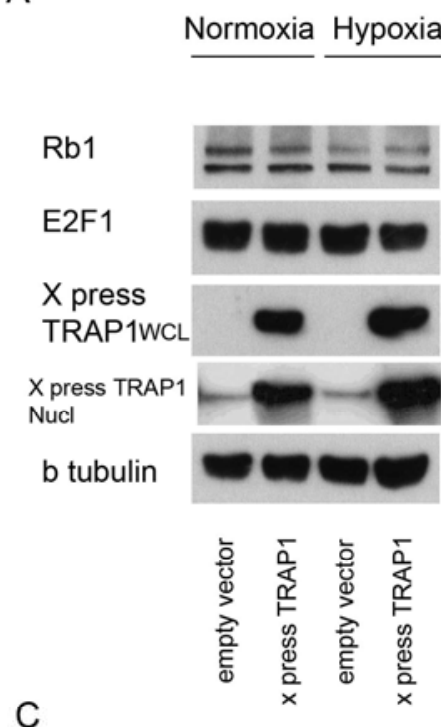

C

Hypoxia MDA231

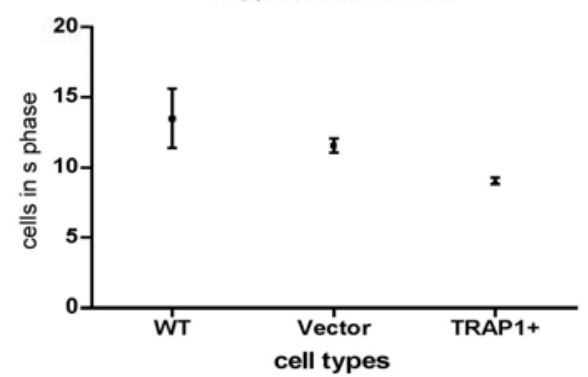

Geldanamycin does not alter the total amount of TRAP1 protein but almost completely abolished the nuclear translocation following hypoxia (Figure 4a). Following the inhibition of TRAP1 nuclear translocation, there is a decrease in hypoxia treated cells of the amount of TRAP1-RB1 complexes associated with a reduction in RB1/E2F1 co-complexes. Levels of E2F1 protein levels were not affected (Figure 4b). TaqMan RT-PCR analysis showed that treatment of MCF7 cells with geldanamycin did not alter the mRNA levels of TRAP1, RB1 and E2F1 (Figure 4c).

\section{Restoration of TRAP1 Expression Enhances RB1/E2F1 Interaction and Inhibits Proliferation}

To further evaluate the effect of TRAP1 on RB1/E2F1 interactions, TRAP1 expression was

B
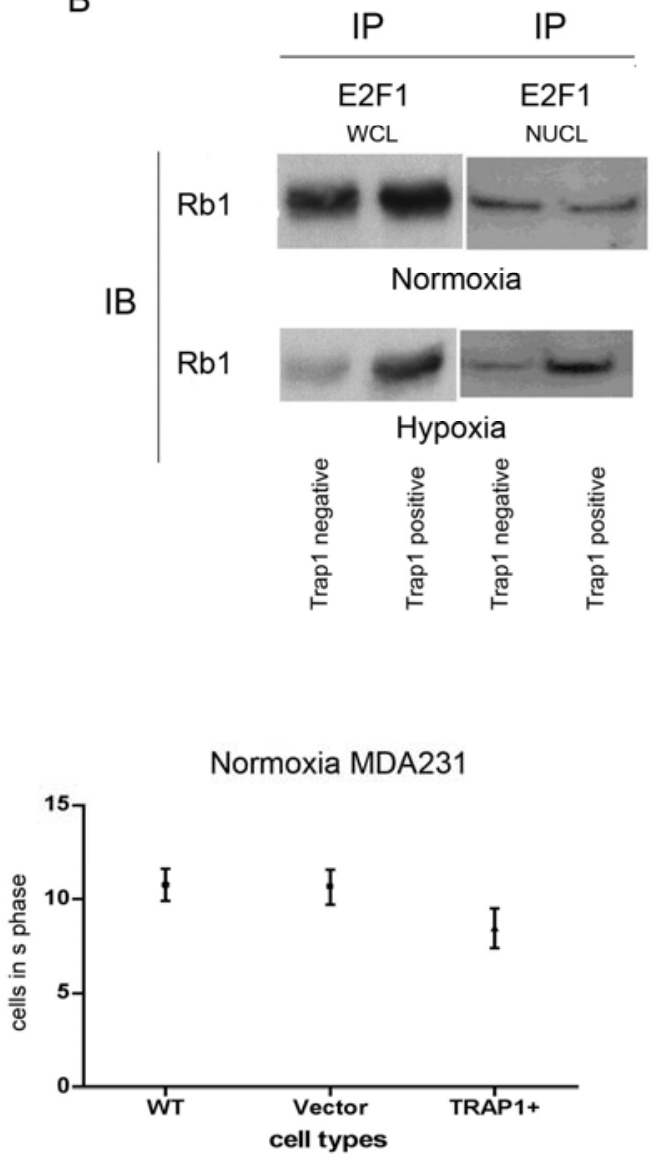

Figure 5: Restoration of TRAP1 expression in MDA231 cells.

A. MDA231 cells were transfected with an empty vector (Mock) or TRAP1-pcDNA (TRAP1) and cultured in normoxia for 32h being subjected to $16 \mathrm{~h}$ hypoxia $(\mathrm{H})$ or cultured for a further $16 \mathrm{~h}$ in normoxia $(\mathrm{N})$. No change in RB1 and E2F1 levels were observed after TRAP1 expression restoration. Lysates were resolved on 10\% SDS-PAGE and immunoblotted. $\beta$-tubulin served as a loading control.

B. MDA231 cells were treated as above and subject to immunoprecipitation (IP) and immunoblott (IB). After hypoxia, RB1/E2F1 complex is almost completely disappeared in mock transfected cells (TRAP1-). But it is maintained when TRAP1 expression is restored following transfection with TRAP1-pcDNA both in WCL and nuclear fraction.

C FACS analysis of BrdU-labelling MDA231 cells. Proportion of S phase cells increased in hypoxia with TRAP1 restoration; no significant change in proportion of S phase cells seen in normoxia. Results are representative of 3 repeat experiments. 
restored in MDA231 human breast adenocarcinoma cells which are deficient in TRAP1 expression but possess functional RB1 [24]. MDA231 cells transfected with empty vector served as a negative control. Whole cell lysates, as well as nuclear and cytoplasmic fractions, were immunoprecipitated with anti-E2F1 and immunoblotted with anti-Rb. Restoration of TRAP1 expression did not appear to alter the total cellular RB1 and E2F1 levels in both normoxia and hypoxia (Figure 5a). No obvious increases in RB1/E2F1 coimmunocomplexes were observed following TRAP1 reexpression in normoxia, while a marked increase of RB1/E2F1 interaction was observed both in WCL and nuclear fractionation when TRAP1-expressing MDA231 cells were subjected to hypoxia (Figure $5 \mathbf{b}$ ).

Having observed that the restoration of TRAP1 expression enhanced the interaction between RB1 and E2F1 in nuclear extracts, the effect on cell proliferation was evaluated. Wild type, empty vector and TRAP1 transfected MDA231 cells were incubated with BrdU to label cells in the $S$ phase and analysed using flow cytometry. A decrease in the proportion of cells entering into the S phase was noted when TRAP1 was re-expressed in MDA231 cells subjected to hypoxia. This was statistically significant $(P=0.0007)$ (Figure 5c). No statistically significant reduction in the $S$ phase fraction was observed following TRAP1 re-expression in cells cultured in normoxia $(P=0.11)$ (Figure $5 \mathrm{c}$ ). These findings were in keeping with coimmunoprecipitation studies that showed a significant increase in RB1/E2F1 co-immunocomplexes only in hypoxia. These findings also complemented observations in TRAP1 knockdowns where TRAP1 loss resulted in an increased tendency of cells entering into the S phase under hypoxic condition.

\section{TRAP1 Expression was Lost in some Types of Human Tumors Compared to its Normal Tissues}

We investigated a large series of tumors compared to their normal tissue to examine the TRAP1 expression profiles in tumors. Immunostaining of paraffin embedded normal tissues demonstrated cytoplasmic expression in several cell types (Figure 6A, D, G, J, M and P). Staining on tumor tissue arrays showed that while some tumors have a strong cytoplasmic and/or nuclear staining, others are negative (Figure $6 \mathrm{E}, \mathbf{F}, \mathbf{H}, \mathbf{I}, \mathbf{K}, \mathbf{L}, \mathbf{M}, \mathbf{N}, \mathbf{O}, \mathbf{Q}, \mathbf{R}$ ). We observed in this study that TRAP1 was widely expressed in many normal tissues. While its expression was retained in tumors, in particular breast, lung and head and neck carcinomas, significant loss of TRAP1 expression was observed in non-Hodgkin Lymphomas, pancreatic neuroendocrine tumors and lung adenocarcinomas (A summary of the results on 630 tumors and normals were shown in supporting information S6 and S7).

These results correspond to our validation using TaqMan real time quantitative PCR where the TRAP1 mRNA levels were found to be lower in non-small cell lung carcinoma, acute myeloid leukaemia and ductal breast carcinoma compared to the corresponding normal tissues but not in head and neck carcinomas (RT-PCR results in supporting information S8).

\section{TRAP1 Correlated with RB1 Expression in Human Tumor Tissues}

We evaluated the correlation of expression of TRAP1 and RB1 in variety of human malignancies including lung, head and neck, pancreatic neurendocrine and $\mathrm{B}$ and $\mathrm{T}$ cell lymphomas. In lung carcinoma, total of 108 cases were examined. Nuclear TRAP1 expression showed a significant positive correlation with RB1 expression ( $P=0.04$, OR 2.22, $95 \% \mathrm{Cl} 1.02-4.86)$, with lung tumors expressing nuclear TRAP1 being twice as likely to express RB1. When NSCLCs (squamous cell carcinoma and adenocarcinoma) were analysed separately from SCLC, nuclear TRAP1 expression positively correlated with RB1 only among NSCLCs $(P=0.004$, OR=3.93, $95 \%$ Cl $1.50-10.29$ ) (Table 1a). NSCLCs expressing TRAP1 exclusively within the cytoplasm were 3 times more likely not to express RB1 ( $P=0.02$, OR $3.47,95 \%$ $\mathrm{Cl} 0.10-0.80$ ) as compared to tumors that expressed TRAP1 in both the nucleus and cytoplasm (Table 1b). There was no correlation between nuclear and cytoplasmic TRAP1 expression and RB1 in SCLC (Table 1c). Similarly, we evaluated 133 cases of head \& neck carcinomas, 36 of pancreatic neuroendocrine tumors and 254 non-Hodgkin lymphomas. No significant correlation of TRAP1 and RB1 expression was observed in head \& neck carcinomas (data not shown). A strong positive correlation of cytoplasmic TRAP1 expression with RB1 was observed in pancreatic neuroendocrine tumors. Tumors expressing TRAP1 in the cytoplasm were 8 times more likely to express RB1 ( $P=0.04$, OR $7.58,95 \%$ Cl 1.31 43.90). TRAP1 expression in the cytoplasm was correlated with RB1 expression in NHL, particularly in DLBCLC ( $P=0.01$, OR $4.94,95 \% \mathrm{Cl} 1.53-15.94)$.

TRAP1 Expression in Breast Cancer: ClinicoPathological Correlations

We investigated the correlation between TRAP1 expression and various standard clinico-pathological 

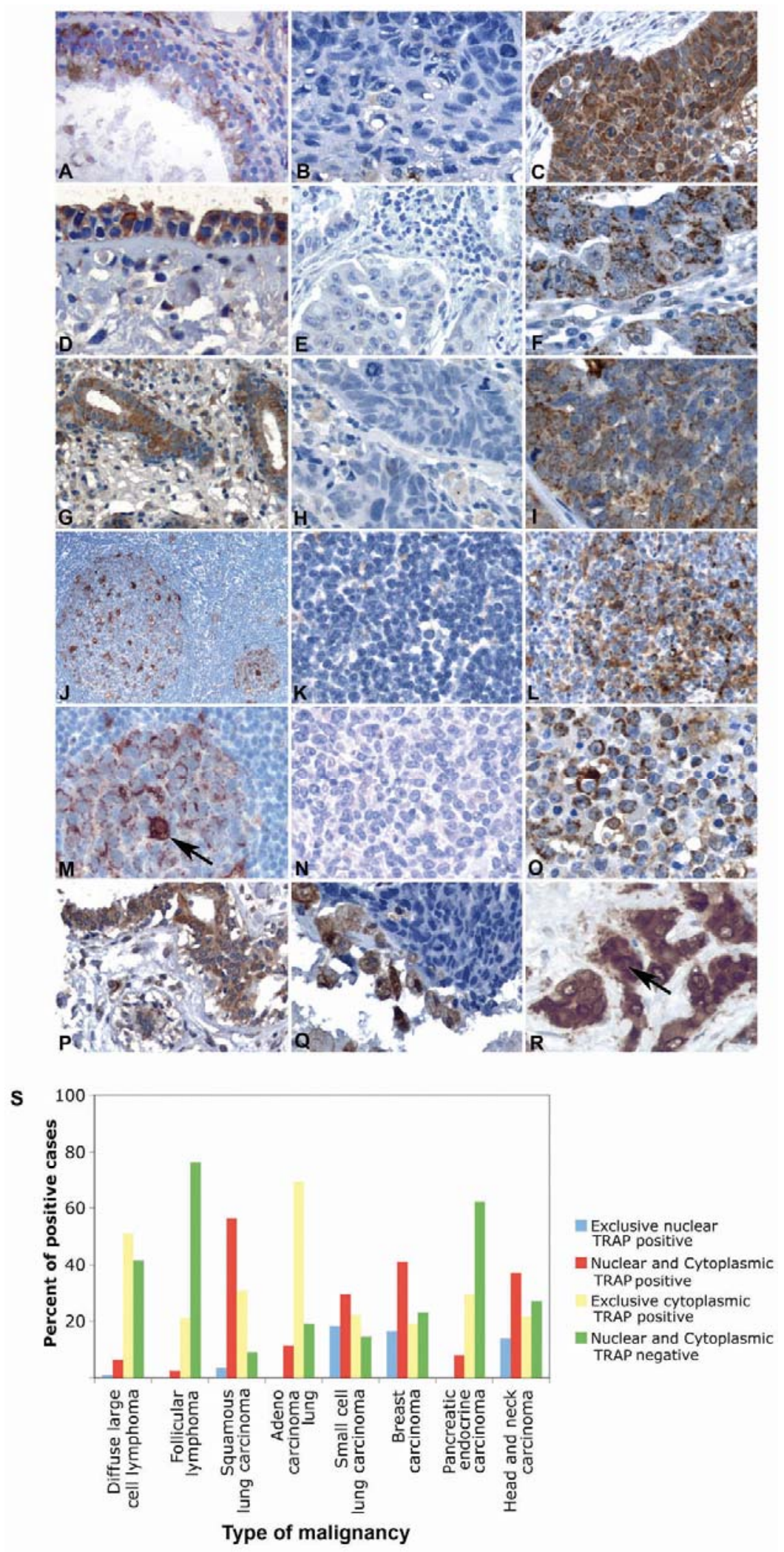

Figure 6: Expression of TRAP1 proteins in normal and neoplastic tissues.

Variable expression of cytoplasmic TRAP1 in A, D bronchial mucosa, G bronchial glands, J, M germinal centres and macrophages (arrow) and $\mathbf{P}$ breast glandular epithelium. Examples of completely TRAP1 negative tumours (lung B carcinoma, $\mathbf{E}$ adenocarcinoma and $\mathbf{H}$ small cell, $\mathbf{K}$ follicular lymphoma, $\mathbf{N}$ large $\mathbf{B}$ cell lymphoma and $\mathbf{Q}$ breast ductal carcinoma). However when the tumour cells are positive $(\mathbf{C}, \mathbf{F}, \mathbf{I}, \mathbf{L}, \mathbf{O}, \mathbf{R})$, a variable number of cells with nuclear staining can be seen $(\mathbf{R}$ arrow). Nuclear staining in tumours could be predicted by the finding that TRAP1 migrate to the nucleus when stress occurs. S. The Percentage of positive and negative cases in a large series of different tumours. 
Table 1: TRAP1 Correlation with RB1 Expression in Lung Carcinomas

Table 1a: Correlation Analysis of Nuclear TRAP1 and RB1 Expression, and of Cytoplasmic TRAP1 and RB1 Expression in NSCLC ( $n<81$ Because Data Not Available)

\begin{tabular}{|c|c|c|c|c|c|c|}
\hline & $\begin{array}{c}\text { Nuclear TRAP1 } \\
\text { Positive } \mathbf{n = 3 7}\end{array}$ & $\begin{array}{c}\text { Nuclear TRAP1 } \\
\text { Negative } \\
\mathbf{n}=\mathbf{4 4}\end{array}$ & P value & $\begin{array}{c}\text { Cytoplasmic } \\
\text { TRAP1 Positive } \\
\mathbf{n}=\mathbf{6 8}\end{array}$ & $\begin{array}{c}\text { Cytoplasmic } \\
\text { TRAP1 Negative } \\
\mathbf{n = 1 3}\end{array}$ & $\begin{array}{c}\text { P value } \\
\text { RB1 }\end{array}$ \\
\hline \hline Positive & 28 & 19 & 0.004 & 41 & 6 \\
negative & 9 & 24 & & 27 & 6 \\
\hline
\end{tabular}

Table 1b: Correlation Analysis of TRAP1 and RB1 Expression, Comparing Exclusive Cytoplasmic TRAP1 Expression Versus Nuclear and Cytoplasmic TRAP1 Expression in NSCLC

\begin{tabular}{|c|c|c|c|}
\hline & $\begin{array}{c}\text { Exclusive cytoplasmic TRAP1 } \\
\mathbf{n = 3 3}\end{array}$ & $\begin{array}{c}\text { Nuclear and cytoplasmic TRAP1 } \\
\mathbf{n}=\mathbf{3 5}\end{array}$ & P value \\
\hline \hline RB1 & 15 & 26 & 0.02 \\
Positive & 18 & 9 & \\
Negative & & \\
\hline
\end{tabular}

Table 1c: Correlation Analysis of Nuclear TRAP1 and RB1 Expression, and of Cytoplasmic TRAP1 and RB1 Expression in SCLC ( $\mathrm{n}<27$ Because Data Not Available)

\begin{tabular}{|c|c|c|c|c|c|c|}
\hline & $\begin{array}{c}\text { Nuclear TRAP1 } \\
\text { Positive } \mathbf{n = 1 3}\end{array}$ & $\begin{array}{c}\text { Nuclear TRAP1 } \\
\text { Negative } \\
\mathbf{n = 1 4}\end{array}$ & P value & $\begin{array}{c}\text { Cytoplasmic } \\
\text { TRAP1 Positive } \\
\mathbf{n}=14\end{array}$ & $\begin{array}{c}\text { Cytoplasmic } \\
\text { TRAP1 Negative } \\
\mathbf{n = 1 3}\end{array}$ & $\begin{array}{c}\text { P value } \\
\text { RB1 }\end{array}$ \\
\hline \hline Positive & 0 & 2 & 0.48 & 0 & 0.22 \\
Negative & 12 & 11 & & 13 & 10 \\
\hline
\end{tabular}

parameters in 423 invasive breast carcinomas for which detailed data and follow up were available. 352 tumors were also evaluated for RB1 expression that was observed in the nucleus of 215 tumors (61\%), with a median intensity of 2 in a median percentage of $80 \%$ of cells (Table 2a). Tumors expressing TRAP1 in the nucleus were 2.7 times more likely to express RB1. There was no correlation between cytoplasmic TRAP1 expression and RB1 expression (Table 2a). Nuclear TRAP1 expression was inversely associated with the risk of disease recurrence (Table 2b). Accordingly, patients expressing TRAP1 in the nucleus had a significantly longer 5-year and 10-year disease-free survival (Figure $7 \mathbf{a} \& \mathbf{b}$ ) as also did those expressing RB1 (see supporting information S9). Cytoplasmic TRAP1 expression was significantly correlated with tumors being of high grade status grade $(P=0.03)$. There was no significant correlation with patient age, tumor size, nodal and ER status or with the risk of recurrence and disease-free survival $(P>0.05)$ (Table 2a).

\section{DISCUSSION}

The RB1/E2F1 pathway is critical in the initiation of DNA replication and it is disrupted in virtually all human cancers [25]. We have previously demonstrated that TRAP1-positive cells contain a high level of cell proliferating genes, whilst TRAP1-negative cells contain a high level of genes involved in cell cycle and metastases [2]. The importance of TRAP1 as a chaperon to RB1 [1] stimulated our investigation as to whether the loss of TRAP1 expression would affect the cellular response to hypoxia following the impairment of RB1 function.

At the cellular level, the two most common responses to hypoxia are either induction of apoptosis [23] or cell proliferation arrest [24, 26]. One of the most specific mechanisms of cell cycle arrest following hypoxia is the hypo-phosphorylation of retinoblastoma susceptibility gene (RB1) leading to arrest at the G1/S checkpoint [27-29]. Cell cycle block in severe hypoxia 
Table 2: Clinico-Pathological Correlations in Breast Carcinomas

Table 2a: Univariate Correlation Analysis Between Nuclear and Cytoplasmic TRAP1 Expression and Standard ClinicPathological Parameters and RB1 Expression

\begin{tabular}{|c|c|c|c|c|c|c|}
\hline & $\begin{array}{l}\text { Nuclear TRAP1 } \\
\text { positive } \\
(n=264)\end{array}$ & $\begin{array}{l}\text { Nuclear TRAP1 } \\
\text { negative } \\
(n=159)\end{array}$ & $P$ value & $\begin{array}{l}\text { Cytoplasmic TRAP1 } \\
\text { positive } \\
(n=292)\end{array}$ & $\begin{array}{c}\text { Cytoplasmic TRAP1 } \\
\text { negative } \\
(n=131)\end{array}$ & $P$ value \\
\hline $\begin{array}{l}\text { Patient age } \\
\text { Median (yr) }\end{array}$ & 58.0 & 57.0 & 0.94 & 58.0 & 58.0 & 0.53 \\
\hline $\begin{array}{l}\text { Tumour size } \\
\text { Median (mm) }\end{array}$ & 21.0 & 22.5 & 0.62 & 23.0 & 20.0 & 0.29 \\
\hline $\begin{array}{c}\text { Tumour grade } \\
\qquad \begin{array}{c}1 \\
2 \\
3\end{array}\end{array}$ & $\begin{array}{l}39 \\
92 \\
69\end{array}$ & $\begin{array}{l}21 \\
45 \\
55\end{array}$ & 0.12 & $\begin{array}{c}35 \\
102 \\
94\end{array}$ & $\begin{array}{l}25 \\
35 \\
30\end{array}$ & 0.03 \\
\hline $\begin{array}{c}\text { Nodal status } \\
\text { Positive } \\
\text { Negative }\end{array}$ & $\begin{array}{l}113 \\
129\end{array}$ & $\begin{array}{l}61 \\
90\end{array}$ & 0.22 & $\begin{array}{l}120 \\
150\end{array}$ & $\begin{array}{l}54 \\
69\end{array}$ & 0.92 \\
\hline $\begin{array}{l}\text { ER status } \\
\text { Positive } \\
\text { Negative }\end{array}$ & $\begin{array}{c}177 \\
66\end{array}$ & $\begin{array}{c}102 \\
51\end{array}$ & 0.19 & $\begin{array}{c}187 \\
86\end{array}$ & $\begin{array}{l}92 \\
31\end{array}$ & 0.20 \\
\hline $\begin{array}{c}\text { Recurrence } \\
\text { First } 5 \text { years } \\
\text { Positive } \\
\text { Negative } \\
\text { First } 10 \text { years } \\
\text { Positive } \\
\text { Negative }\end{array}$ & $\begin{array}{c}59 \\
186 \\
85 \\
160\end{array}$ & $\begin{array}{l}57 \\
98 \\
70 \\
85\end{array}$ & $\begin{array}{l}0.01 \\
0.04\end{array}$ & $\begin{array}{c}74 \\
200 \\
103 \\
171\end{array}$ & $\begin{array}{l}42 \\
84 \\
52 \\
74\end{array}$ & $\begin{array}{l}0.20 \\
0.48\end{array}$ \\
\hline $\begin{array}{c}\text { RB1 } \\
\text { Positive } \\
215 \\
\text { Negative } \\
137\end{array}$ & $\begin{array}{c}160 \\
71\end{array}$ & $\begin{array}{l}55 \\
66\end{array}$ & $<0.0001$ & $\begin{array}{c}158 \\
92\end{array}$ & $\begin{array}{l}57 \\
45\end{array}$ & 0.20 \\
\hline
\end{tabular}

( $n<423$ because data not available).

Table 2b: Multivariate Analysis Cox Regression Model of Disease-Free Survival for Standard Clinic-Pathological Parameters and Nuclear TRAP1 Expression (Data for all the Parameter Analysed were Available for 160 Patients)

\begin{tabular}{|c|c|c|c|}
\hline & Hazard ratio & 95\% Cl & P value \\
\hline \hline Nuclear TRAP1 & 0.81 & $0.50-1.31$ & 0.39 \\
\hline Tumour grade & 1.11 & $0.79-1.56$ & 0.53 \\
\hline Tumour size & 3.08 & $1.84-5.16$ & $<0.001$ \\
\hline Nodal status & 2.89 & $1.72-4.86$ & $<0.001$ \\
\hline
\end{tabular}

has been reported to be caused by inactivation of enzymes responsible for nucleotide synthesis, leading to inhibition of DNA replication [30, 31]. However in tumors, hypoxia is associated with more aggressive clinical characteristics [23]. It has been widely reported that after an exposure to hypoxia of $4-12$ hours, RB1 switches from an inactive phosphorylated form to an active hypo-phosphorylated conformation inducing an arrest of the cell in $\mathrm{G} 1$ [24, 29, 32, 33]. A mechanism by which hypo-phosphorylation of RB1 is regulated in 

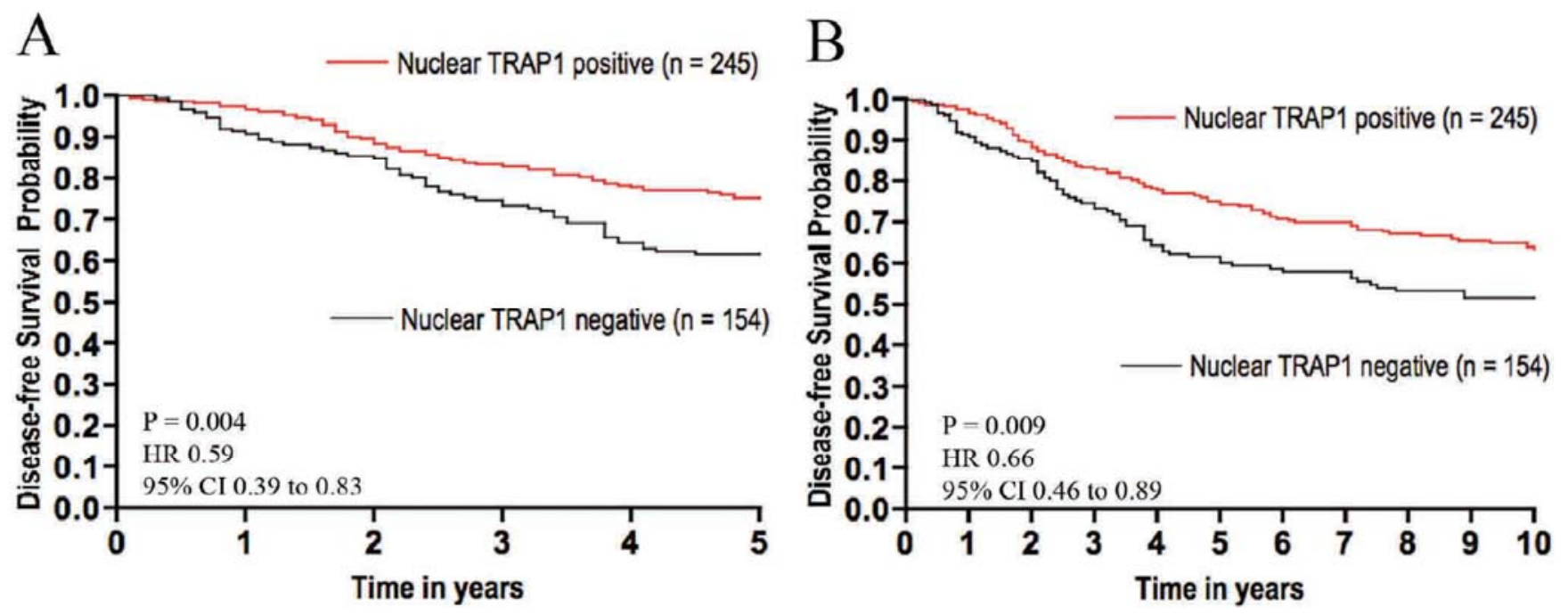

Figure 7: Disease-free survival in breast carcinoma stratified according to nuclear TRAP1 expression.

There is significantly better 5-year $(\mathbf{A})$ and 10 year $(\mathbf{B})$ disease-free survival in patient whose have tumours with positive nuclear staining compared to the one with negative nuclear staining for TRAP1. However, there is no difference between patients classified according to cytoplasmic staining (data not show).

hypoxia is that Hif1 inhibits CyclinE and CDK2 activity, presumably by increasing p27 expression, preventing RB1 hyper-phosphorylation and therefore inducing arrest in $\mathrm{G} 1$ [34].

We proposed an additional hypothesis that impairment of RB1 function, due to the loss of TRAP1, could therefore be the prototype for a new oncogenic mechanism in which a tumor suppressor protein activity is lost. This is because of inactivation due to the lack or reduced availability of its chaperons.

First, we observed that in TRAP1 knock-down MCF7 cells, there is a decline in the levels of RB1 protein and RB1/E2F1 complexes resulting in an increase in cellular proliferation with more cells present in the $S$ phase when cells exposed in hypoxia, indicating that knock-down TRAP1 facilitates the G1/S transition. These effects are reversed if TRAP1 expression is re-stored in the MDA231 cells. We then showed that, in a hypoxic environment, TRAP1 is translocated to the nucleus and links to RB1. This nuclear translocation occurs between 16-24 hours of hypoxia. This effect seems to be an early event when cells are under hypoxic stress, as we found that TRAP1 nuclear localization decreased after 24 hours of exposure to hypoxia. Our findings are in keeping with the original report by Chen et al. [1] that TRAP1 translocates to the nucleus and re-folds RB1 after a shock. In the absence of the chaperon, the misfolded protein becomes unable to link to its target and is probably degraded by the proteasomal pathway in a similar way to most other misfolded proteins [35].

To establish whether the accumulation of more cells in S phase was truly due to RB1 inactivation, we looked at RB1 interactions with E2F1 and found that the ability of RB1 linking to E2F1 is impaired in the nuclear extracts when TRAP1 deficient cells were exposed to hypoxia, despite an increase in hypo-phosphorylated RB1. Furthermore, re-expression of TRAP1 in the MD23 cell line, which is TRAP1 negative and has wild type RB1, showed that less cells enter $S$ phase following exposure to hypoxia whilst increasing the amount of RB1 forming complexes with E2F1 observed in the nuclear fractionation.

Geldanamycin is a benzoquinone ansamycin antibiotic that inhibits the chaperon function of HSP90 by targeting its ATPase domain and interfering with its ability to hydrolyse ATP [36, 37]. TRAP1 was also found to possess ATPase activity that was similarly inhibited by Geldanamycin [2]. In order to determine whether ATPase activity was important for the chaperon function of TRAP1, MCF7 cells were treated with Geldanamycin prior to hypoxia. Treatment with Geldanamycin showed that low levels of TRAP nuclear localization resulted in the loss of RB1 and RB1-E2F1 complexes, although the expression of TRAP1 remained at normal levels, suggesting that Geldanamycin interfered with the ability of TRAP1 to associate with RB1 rather than its level of expression. This result also demonstrates that the ability of TRAP1 
in linking to and re-folding RB1 is strictly associated with a nuclear localization. Loss of RB1 after 12 hours of Herbamycin A treatment of cell lines has also been reported but no explanation for it has been provided [38]. Herbamycin A inactivates HSP90 by a mechanism similar to Geldanamycin. It is possible that it also inactivates TRAP1 leading to a decline in RB1 protein levels.

TRAP1 protein is ubiquitously expressed in normal human [5], murine [1] and rat [6] tissues. Our systematic review of individual patient DNA microarray data by a meta-analysis shows a loss of TRAP1 mRNA in many types of tumor compared to normal tissue [20]. In the present study, we confirmed by immunohistochemistry that TRAP1 protein is ubiquitously expressed in normal human tissues. We also confirmed that, in several types of tumors, TRAP1 protein expression is lost compared to its corresponding normal tissue. There were reports showing an increased expression of TRAP1 in tumors compared to normal tissue, e.g. Kang et al. [7] reported that they only immunostained four types of normal tissues: exocrine pancreas, breast, colon and lung (alveoli) and 2 cases for each type of tumour (a total of 8 cases) which might explain why they missed negative tumors and most of the positive normal tissues.

Our findings in the correlation expression of TRAP1 and RB1 in a variety of human tumor tissues, particularly in NSCLC and breast tumors, suggested that TRAP1 was associated with RB1 when it was expressed within the nucleus and that the association was lost when TRAP1 was excluded from the nucleus. This was in keeping with previous postulation that TRAP1 associated with RB1 only when both were present in the same subcellular compartment [1] and, since RB1 is primarily a nuclear protein, TRAP1 may chaperone RB1 only when it is present in the nucleus as well. We observed that TRAP1 was not associated with RB1 expression in head \& neck tumors. In addition, the TRAP1 mRNA levels were up-regulated in head \& neck tumors, thus it is possible to speculate that TRAP1 does not function as a molecular chaperone of RB1 in head \& neck tumors since a loss, rather than an overexpression, of TRAP1 would potentially deregulate the cell cycle and facilitate malignant progression. This raised the possibility that TRAP1 may modulate cellular pathways other than the cell cycle in head \& neck tumors. This would not be unexpected since TRAP1 belongs to the HSP family of proteins, which are known to be involved in a wide range of cellular processes, and this might possibly account for the findings of the meta-analysis that TRAP1 gene expression was down-regulated in certain tumors but up-regulated in others.

Finally, we examined the correlation of the expression of TRAP1 and the level of RB1 expression in human ductal breast cancer. We investigated the correlation between its expression and various standard clinico-pathological parameters in 423 infiltrating ductal breast carcinomas for which detailed data and follow up were available. We found a positive association between a lack of nuclear TRAP1 and a loss of RB1 expression. Furthermore, lack of nuclear TRAP1 was associated with a shorter disease free survival that is consistent with its putative suppressor activity via the action of RB1. Structural alterations of the RB1 gene are one of the most important molecular changes in breast cancer [39] though several tumours have been identified with normal genes but with loss of protein expression [40]. Several studies have indicated a correlation between the RB1/E2F1 pathway and prognosis [41] in this type of tumor. Although the genetic status of the RB1 gene in our patient cohort is unknown, the functional link between the TRAP1 and RB1 tumor suppressor may provide a predictive marker for future clinical studies. It is of interest that cytoplasmic expression of TRAP1 is associated with grade 3 , more aggressive, breast carcinomas. If this association is confirmed in larger studies, the association between cytoplasmic TRAP1 and more aggressive tumours might reflect a differential function for this gene in different cellular localisations.

\section{CONCLUSIONS}

In summary, we have investigated the role of TRAP1 in maintaining RB1 function in response to hypoxia. Lack of TRAP1 leading to RB1 impairment would allow tumor cells to grow in hypoxia escaping the physiological cell cycle arrest provided by RB1. These observations are consistent with the hypothesis that $\mathrm{G} 1$ arrest in hypoxia may be regulated through activation of the growth suppressive function of RB1. Our results also revealed the complex patterns of TRAP1 expression in human malignant tissues and its correlation with RB1. The importance of our results is twofold. First, we described a new molecular pathway leading to RB1 inactivation. This novelty is evident from a recently published extended map of pathways leading to RB1 inactivation that does not include TRAP1 [42]. The second important point is that we 
have provided a concept that the loss of tumor suppressor RB1 gene in association with decreased TRAP1 expression is an early event when tumor cells encounter hypoxia. The closest similar hypothesis is the observation in Drosophila Melanogaster that the tumor suppressor gene TID (tumorous imaginal discs) has a sequence predicting a chaperon function [43].

We propose that loss of TRAP1 causing RB1 inactivation could be the prototype of a new oncogenic mechanism by which tumor suppressor genes are inactivated by conformational alterations, following the absence of their chaperons. However, the RB1 suppressor effect in hypoxia seems to occur early and have a short duration (within 24 hours in cell culture). Whether its inactivation following shock has any durable consequences for tumor growth remains to be established. We are now focusing our work on the finding of genes regulated by TRAP1/RB1, in the setting of a time course exposure of hypoxia, to study the long term effect of TRAP1/RB1 in the response to hypoxia.

\section{COMPETING INTERESTS}

None declared.

\section{AUTHORS' CONTRIBUTIONS}

HJ: conceived the study, participated in its design and coordination, performed the siRNA and transfection experiments, conducted statistical analysis and drafted the manuscript. TE: participated in the design and coordination of the study, evaluated TRAP1 TMA immunohistochemistry, performed the siRNA and transfection experiments, conducted statistical analysis and drafted the manuscript. CL: performed TRAP1 TMA immunohistochemistry. SZ: performed TRAP1 TMA immunohistochemistry and cell culture. TH: participated in the tumor cases immunohistochemistry and helped with the selecting of cases. DD: performed cell culture and FACS analysis. CA: participated in the design of the study and provided funding. GK: participated in the design and coordination of the study, provided funding support and edited the manuscript. PF: conceived the study, participated in its design and coordination, and edited the manuscript. All authors read and approved the final manuscript.

\section{ACKNOWLEDGEMENTS AND FUNDING}

We thank Dr A. Inche, P. North, Dr K. Micklem, Dr A. Graham and Mrs M. Smart for their great help with the preparation of the figures and discussion the manuscript. Dr Ern Yu Tan was supported by National Medical Research Council (NMRC) of Singapore Totalisator Board Medical Research Fellowship. This work was in part supported by Cancer Research UK grants.

\section{SUPPLEMENTAL MATERIALS}

The supplemental materials can be downloaded from the journal website along with the article.

\section{REFERENCES}

[1] Chen CF, Chen Y, Dai K, Chen PL, Riley DJ, Lee WH. A new member of the hsp90 family of molecular chaperones interacts with the retinoblastoma protein during mitosis and after heat shock. Mol Cell Biol 1996; 16: 4691-9.

[2] Liu D, Hu J, Agorreta J, Cesario A, Zhang Y, Harris AL, et al. Tumor necrosis factor receptor-associated protein 1(TRAP1) regulates genes involved in cell cycle and metastases. Cancer Lett 2010; 296(2): 194-205.

http://dx.doi.org/10.1016/j.canlet.2010.04.017

[3] Felts SJ, Owen BA, Nguyen P, Trepel J, Donner DB, Toft DO. The hsp90-related protein TRAP1 is a mitochondrial protein with distinct functional properties. J Biol Chem 2000; 275: 3305-12.

http://dx.doi.org/10.1074/jbc.275.5.3305

[4] Pridgeon JW, Olzmann JA, Chin LS, Li L. PINK1 Protects against Oxidative Stress by Phosphorylating Mitochondrial Chaperone TRAP1. PLoS Biol 2007; 5: e172. http://dx.doi.org/10.1371/journal.pbio.0050172

[5] Song HY, Dunbar JD, Zhang YX, Guo D, Donner DB. Identification of a protein with homology to hsp90 that binds the type 1 tumor necrosis factor receptor. J Biol Chem 1995; 270: 3574-81.

http://dx.doi.org/10.1074/jbc.270.8.3574

[6] Cechetto JD, Gupta RS. Immunoelectron microscopy provides evidence that tumor necrosis factor receptorassociated protein 1 (TRAP-1) is a mitochondrial protein which also localizes at specific extramitochondrial sites. Exp Cell Res 2000; 260: 30-9.

http://dx.doi.org/10.1006/excr.2000.4983

[7] Kang BH, Plescia J, Dohi T, Rosa J, Doxsey SJ, Altieri DC. Regulation of tumor cell mitochondrial homeostasis by an organelle-specific Hsp90 chaperone network. Cell 2007; 131: 257-70.

http://dx.doi.org/10.1016/j.cell.2007.08.028

[8] Simmons AD, Musy MM, Lopes CS, Hwang LY, Yang YP, Lovett M. A direct interaction between EXT proteins and glycosyltransferases is defective in hereditary multiple exostoses. Hum Mol Genet 1999; 8: 2155-64.

http://dx.doi.org/10.1093/hmg/8.12.2155

[9] Montesano Gesualdi N, Chirico G, Pirozzi G, Costantino E, Landriscina M, Esposito F. Tumor necrosis factor-associated protein 1 (TRAP-1) protects cells from oxidative stress and apoptosis. Stress 2007; 10: 342-50. http://dx.doi.org/10.1080/10253890701314863

[10] Neckers L, Kern A, Tsutsumi S. Hsp90 inhibitors disrupt mitochondrial homeostasis in cancer cells. Chem Biol 2007; 14: 1204-6.

http://dx.doi.org/10.1016/j.chembiol.2007.11.002

[11] Takemoto K, Miyata S, Takamura H, Katayama T, Tohyama M. Mitochondrial TRAP1 regulates the unfolded protein response in the endoplasmic reticulum $2011 ; 58(8)$ : 880-7. 
[12] Im CN, Lee JS, Zheng Y, Seo JS. Iron chelation study in a normal human hepatocyte cell line suggests that tumor necrosis factor receptor-associated protein 1 (TRAP1) regulates production of reactive oxygen species. J Cell Biochem 2007; 100: 474-86. http://dx.doi.org/10.1002/jcb.21064

[13] Masuda Y, Shima G, Aiuchi T, Horie M, Hori K, Nakajo S, et al. Involvement of tumor necrosis factor receptor-associated protein 1 (TRAP1) in apoptosis induced by betahydroxyisovalerylshikonin. J Biol Chem 2004; 279: 42503-15. http://dx.doi.org/10.1074/jbc.M404256200

[14] Hua G, Zhang Q, Fan Z. Heat shock protein 75 (TRAP1) antagonizes reactive oxygen species generation and protects cells from granzyme M-mediated apoptosis. J Biol Chem 2007; 282: 20553-60.

http://dx.doi.org/10.1074/jbc.M703196200

[15] Costantino E, Maddalena F, Calise S, Piscazzi A, Tirino V, Fersini $A$, et al. TRAP1, a novel mitochondrial chaperone responsible for multi-drug resistance and protection from apoptotis in human colorectal carcinoma cells. Cancer Lett 2009; 279: 39-46.

http://dx.doi.org/10.1016/j.canlet.2009.01.018

[16] Coller HA, Grandori C, Tamayo P, Colbert T, Lander ES, Eisenman RN, et al. Expression analysis with oligonucleotide microarrays reveals that MYC regulates genes involved in growth, cell cycle, signaling, and adhesion. Proc Natl Acad Sci USA 2000; 97: 3260-5.

http://dx.doi.org/10.1073/pnas.97.7.3260

[17] Fang W, Li X, Jiang Q, Liu Z, Yang $H$, Wang S, et al. Transcriptional patterns, biomarkers and pathways characterizing nasopharyngeal carcinoma of Southern China. J Transl Med 2008; 6: 32. http://dx.doi.org/10.1186/1479-5876-6-32

[18] $\mathrm{Hu}$ J, Bianchi F, Ferguson M, Cesario A, Margaritora S, Granone $\mathrm{P}$, et al. Gene expression signature for angiogenic and nonangiogenic non-small-cell lung cancer. Oncogene 2005; 24: 1212-9. http://dx.doi.org/10.1038/sj.onc. 1208242

[19] Couvelard A, Hu J, Steers G, O'Toole D, Sauvanet A, Belghiti $\mathrm{J}$, et al. Identification of potential therapeutic targets by gene-expression profiling in pancreatic endocrine tumors. Gastroenterology 2006; 131: 1597-10. http://dx.doi.org/10.1053/i.gastro.2006.09.007

[20] Ramasamy A, Mondry A, Holmes C, Altman D. Key Issues in Conducting a Meta-Analysis of Gene Expression Microarray Datasets. PLoS Med 2008; 8(5): 1320-32.

[21] Solimini NL, Luo J, Elledge SJ. Non-oncogene addiction and the stress phenotype of cancer cells. Cell 2007; 130: 986-8. http://dx.doi.org/10.1016/j.cell.2007.09.007

[22] Harris AL. Hypoxia--a key regulatory factor in tumour growth. Nat Rev Cancer 2002; 2: 38-47. http://dx.doi.org/10.1038/nrc704

[23] Ludlow JW, Howell RL, Smith HC. Hypoxic stress induces reversible hypophosphorylation of $\mathrm{pRB}$ and reduction in cyclin A abundance independent of cell cycle progression. Oncogene 1993; 8: 331-9.

[24] Botos J, Smith R, 3rd, Kochevar DT. Retinoblastoma function is a better indicator of cellular phenotype in cultured breast adenocarcinoma cells than retinoblastoma expression. Exp Biol Med (Maywood) 2002; 227: 354-62.

[25] Nevins JR. The Rb/E2F pathway and cancer. Hum Mol Genet 2001; 10: 699-703. http://dx.doi.org/10.1093/hmg/10.7.699

[26] Schmaltz C, Hardenbergh PH, Wells A, Fisher DE. Regulation of proliferation-survival decisions during tumor cell hypoxia. Mol Cell Biol 1998; 18: 2845-54.
[27] Papandreou I, Powell A, Lim AL, Denko N. Cellular reaction to hypoxia: sensing and responding to an adverse environment. Mutat Res 2005; 569: 87-100. http://dx.doi.org/10.1016/j.mrfmmm.2004.06.054

[28] Goda N, Dozier SJ, Johnson RS. HIF-1 in cell cycle regulation, apoptosis, and tumor progression. Antioxid Redox Signal 2003a; 5: 467-73.

http://dx.doi.org/10.1089/152308603768295212

[29] Gardner LB, Li Q, Park MS, Flanagan WM, Semenza GL, Dang CV. Hypoxia inhibits G1/S transition through regulation of p27 expression. J Biol Chem 2001; 276: 7919-26. http://dx.doi.org/10.1074/jbc.M010189200

[30] Loffler M. The biosynthetic pathway of pyrimidine (deoxy)nucleotides: a sensor of oxygen tension necessary for maintaining cell proliferation? Exp Cell Res 1989; 182: 673-80.

http://dx.doi.org/10.1016/0014-4827(89)90271-1

[31] Thelander L, Graslund A, Thelander M. Continual presence of oxygen and iron required for mammalian ribonucleotide reduction: possible regulation mechanism. Biochem Biophys Res Commun 1983; 110: 859-65.

http://dx.doi.org/10.1016/0006-291X(83)91040-9

[32] Amellem O, Pettersen EO. Cell cycle progression in human cells following re-oxygenation after extreme hypoxia: consequences concerning initiation of DNA synthesis. Cell Prolif 1993; 26: 25-35.

http://dx.doi.org/10.1111/j.1365-2184.1993.tb00003.x

[33] Krtolica A, Krucher NA, Ludlow JW. Hypoxia-induced pRB hypophosphorylation results from downregulation of CDK and upregulation of PP1 activities. Oncogene 1998; 17: 2295-304. http://dx.doi.org/10.1038/sj.onc.1202159

[34] Goda N, Ryan HE, Khadivi B, McNulty W, Rickert RC, Johnson RS. Hypoxia-inducible factor 1alpha is essential for cell cycle arrest during hypoxia. Mol Cell Biol 2003b; 23: 35969.

http://dx.doi.org/10.1128/MCB.23.1.359-369.2003

[35] Ma Y, Hendershot LM. The role of the unfolded protein response in tumour development: friend or foe? Nat Rev Cancer 2004; 4: 966-77.

http://dx.doi.org/10.1038/nrc1505

[36] Stebbins CE, Russo AA, Schneider C, Rosen N, Hartl FU, Pavletich NP. Crystal structure of an Hsp90-geldanamycin complex: targeting of a protein chaperone by an antitumor agent. Cell 1997; 89: 239-50. http://dx.doi.org/10.1016/S0092-8674(00)80203-2

[37] Whitesell L, Mimnaugh EG, De Costa B, Myers CE, Neckers LM. Inhibition of heat shock protein HSP90-pp60v-src heteroprotein complex formation by benzoquinone ansamycins: essential role for stress proteins in oncogenic transformation. Proc Natl Acad Sci USA 1994; 91: 8324-28. http://dx.doi.org/10.1073/pnas.91.18.8324

[38] Srethapakdi M, Liu F, Tavorath R, Rosen N. Inhibition of Hsp90 function by ansamycins causes retinoblastoma gene product-dependent G1 arrest. Cancer Res 2000; 60: 3940-6.

[39] T'Ang A, Varley JM, Chakraborty S, Murphree AL, Fung YK. Structural rearrangement of the retinoblastoma gene in human breast carcinoma. Science 1988; 242: 263-6. http://dx.doi.org/10.1126/science.3175651

[40] Varley JM, Armour J, Swallow JE, Jeffreys AJ, Ponder BA, T'Ang $A$, et al. The retinoblastoma gene is frequently altered leading to loss of expression in primary breast tumours. Oncogene 1989; 4: 725-9.

[41] Fung YK, T'Ang A. The role of the retinoblastoma gene in breast cancer development. Cancer Treat Res 1992; 61: 5968.

http://dx.doi.org/10.1007/978-1-4615-3500-34 
[42] Calzone L, Gelay A, Zinovyev A, Radvanyl F, Barillot E. A comprehensive modular map of molecular interactions in RB/E2F pathway. Mol Syst Biol 2008; 4: 173. http://dx.doi.org/10.1038/msb.2008.7
[43] Kurzik-Dumke U, Gundacker D, Renthrop M, Gateff E. Tumor suppression in Drosophila is causally related to the function of the lethal(2) tumorous imaginal discs gene, a dnaJ homolog. Dev Genet 1995; 16: 64-76.

http://dx.doi.org/10.1002/dvg.1020160110

Received on 16-04-2013

Accepted on 07-05-2013

Published on 01-07-2013

DOI: http://dx.doi.org/10.6000/1929-2279.2013.02.03.5

(C) $2013 \mathrm{Hu}$ et al.; Licensee Lifescience Global.

This is an open access article licensed under the terms of the Creative Commons Attribution Non-Commercial License (http://creativecommons.org/licenses/by-nc/3.0/) which permits unrestricted, non-commercial use, distribution and reproduction in any medium, provided the work is properly cited. 